\title{
Earthquake vulnerability zonation of Mashhad urban fabric by combining the quantitative models in GIS, northeast of Iran
}

\author{
Mohammad Reza Mansouri Daneshvar ${ }^{1, *}$, Somayeh Rezayi ${ }^{2}$, Sarah Khosravi ${ }^{3}$ \\ ${ }^{1}$ Department of Physical Geography, Mashhad Branch, Islamic Azad University, Mashhad, Iran \\ ${ }^{2}$ Department of Geography and Rural Planning, University of Sistan and Baluchestan, Zahedan, Iran \\ ${ }^{3}$ Department of Urban Planning and Design, Mashhad Branch, Islamic Azad University, Mashhad, Iran
}

\section{Email address:}

mrm_daneshvar2012@yahoo.com (M. R. M. Daneshvar), s_rezayi2012@yahoo.com (S. Rezayi), sarah.khosravi1@gmail.com (S. Khosravi)

\section{To cite this Article:}

Mohammad Reza Mansouri Daneshvar, Somayeh Rezayi, Sarah Khosravi. Earthquake Vulnerability Zonation of Mashhad Urban Fabric by Combining the Quantitative Models in GIS, Northeast of Iran. International Journal of Environmental Protection and Policy,

Vol. 1, No. 4, 2013, pp. 44-49. doi: 10.11648/j.ijepp.20130104.11

\begin{abstract}
In this study, we determined vulnerability levels of urban fabrics against earthquake risk using spatial factors. Therefore to classify risk vulnerability zones of the Mashhad urban fabric we used parameters such as ratio of open spaces, size of lands differentiation, population density, occupied area by buildings, age of buildings, deteriorated urban fabrics, proximity to faults, and seismic grading. These parameters are derived based on Mashhad municipality districts then weighted by Analytic Hierarchy Process (AHP) and combined by the Standard Score Model in geographic information system (GIS). The results indicated that: first, the central district and districts of eight, three and four in Mashhad have the most fabric vulnerability against earthquakes, respectively. Second, the urban texture of municipal districts containing districts of nine, seven, six and ten have less vulnerability against earthquakes, respectively. Third, the parameters analysis using AHP exhibited the weighty value for lands differentiation parameter while, the correlation test revealed that the strong correlation between deteriorated urban fabrics and the final zoning map ( $\mathrm{R}^{2}$ equal to 0.75$)$.
\end{abstract}

Keywords: Analytic Hierarchy Process (AHP), Geographic Information System (GIS), Standard Score Model, Vulnerability

\section{Introduction}

The recent earthquakes e.g. Kobe (17.1.1995), Gujarat (26.1.2001), Bam (26.12.2003) and Port-au-Prince (12.1.2010) prove once more that for the urban areas to be safe and sustainable, a long-range urban planning must be implemented, based on multidisciplinary risk assessment tools. The challenge of urban susceptibility mapping is to predict the ground motion effects related to various sources, path and site characteristics not just at a single site but over an extended region, and to do so with an acceptable level of reliability (Paskaleva et al, 2007). Nowadays, efforts are focused on expanding the spatial approach to organizing residential and urban areas in regional dimensions (Clark et al, 2009). Most attempts to quantify environmental vulnerability to date refer to specific systems and particular stressors or classes of stressors. For example, Lantada et al,
(2003) applied a GIS methodology for studying the vulnerability and seismic damage scenarios for Barcelona using an index of average vulnerability associated to the residential building typologies of the city. Petermans et al, (2006) used a combination of geological data, field measurements and numerical modelling in a 2D and 3D GIS environment for assessing the local seismic hazard in the urban centre of Brussels. A similar method (VULNERALP) that is based on a simplified approach (seismic inventory of buildings) for vulnerability assessment in moderate-low seismic hazard regions has been applied to Grenoble, France (Gueguen et al, 2007). A numerous of GIS-oriented applications related to the seismic vulnerability and geological hazard are developed in the past. Some of them are dealing with urban vulnerability (Cutter and Mitchell, 2000; Menoni, 2001), emergency support systems (Voulgaris et al, 2003; Youhai et al, 2006), simulation and modeling of earthquake disaster (Xu et al, 2008; Ren and 
Xie, 2004; Zaincenco and Alkaz, 2005) and development of earthquake information systems or hazard mitigation databases (Umemura et al, 2000; Giammarinaro et al, 2003; Martelli et al, 2007; Hampton et al, 2008; Inel et al, 2008). Definitions of geological risk used in researches vary according to applications for which they are used. The risk also depends on how much building is exposed to the hazard and how vulnerable it is to damage. In addition, risk can be seen graphically as a function of three elements, hazard, exposure and vulnerability as illustrated in the risk triangle proposed by Crichton and Salt (2001). In this regard, the vulnerability is the susceptibility of the buildings to the hazard (Fedeski and Gwilliam, 2007). There are essentially two main factors causing vulnerability existence of the risk, and to be at risk (Turner et al, 2003). In fact, the composition of the hazard factor and vulnerability lead to the production of crisis (Prowse, 2003). Accordingly, the most vulnerable places are those that either more exposed to risk or most susceptible to be effected by hazard (De Leon, 2006). Most of the Iran populated areas are located in the earthquake regions and the major cities are located on the mountain hills that are over separated active faults. In recent decade establishing the geographic database to estimate earthquake risk are used in large scale in the field of urban management and GIS programs (JICA, 2000) and are introduced the factors such as geotechnical instability of soil, proximity to faults, the size of open spaces, building and population density, age of urban fabric, open spaces, and access to roads. The experience of the Bam earthquake with a magnitude of 6.3 Richter scale on December 26, 2003 indicates that in order to have a disaster it is enough to have the following three factors: low quality of building construction, high population density and closeness to faults. At the present study, we investigate the urban fabric vulnerability in terms of earthquake hazards at the study area. Our aim is to identify the sensitivity of urban fabric vulnerability against earthquakes by using the combination model of analytic hierarchy process (AHP) and standard score classifications. For this purpose, we prepared an earthquake susceptibility zonation via GIS based on each municipality districts of Mashhad.

\section{Material and Methods}

\subsection{The Study Area}

The Mashhad city is the capital of Khorasan-e-Razavi province with population of 2,410,800 (Statistical center of Iran, 2006) which located in the northeast of Iran $\left(36^{\circ} 37^{\prime}-36^{\circ} 58^{\prime} \mathrm{N}, \quad 59^{\circ} 26^{\prime}-59^{\circ} 44^{\prime} \mathrm{E}\right)$ (Figure 1). The developed urban structure of Mashhad is in area with 292 $\mathrm{km}^{2}$ and the population density of Mashhad is $82.5 \mathrm{p} / \mathrm{ha}$. The spatial analysis of urban topography in GIS indicated that the highest part of the city in the southwest, has an altitude of $1340 \mathrm{~m}$ a.s.l and the lowest part in the northeast has an altitude of $920 \mathrm{~m}$ a.s.l (Figure 2). From the geological viewpoint, this city extended over the strata plain and formed on the thick layers of alluvial sediments. The northern part of the study area is located on Kashaf-roud River and the southern part is laid on Granitic-Batholithic Zone of the Binalod Mountains (Figure 3).

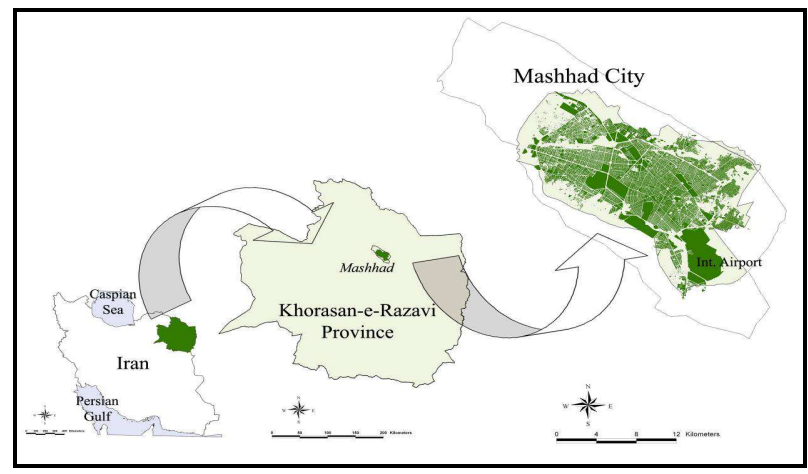

Figure 1. The position of the study area

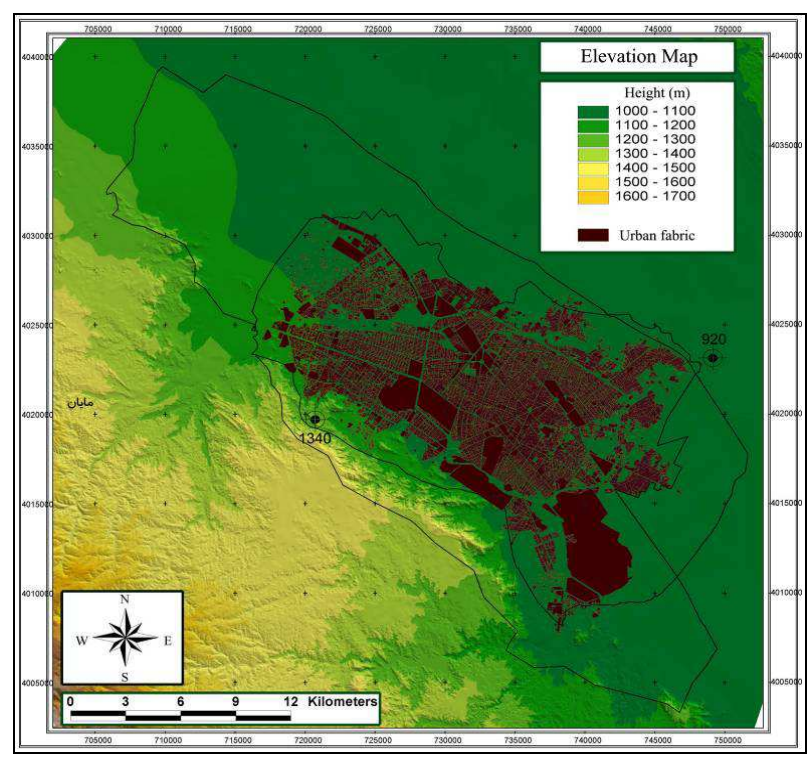

Figure 2. Topographical map of the study area

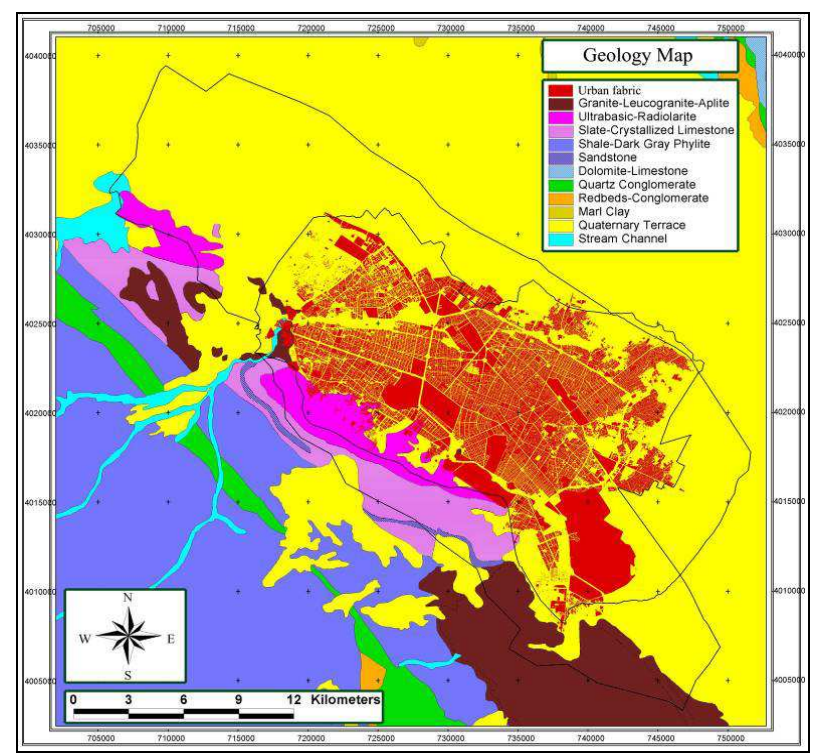

Figure 3. Topographical map of the study area 
Mashhad city is affected by the seismo-tectonics of the Binalod mountainous complex with the trends of faults from the northwest to the southeast. The most effective faults of the Mashhad urban fabric are the Kashaf-roud fault at the northward and the Shandiz-Sangbast fault at the southward. In addition, the city has a semi-arid climate with an annual rainfall of $221.1 \mathrm{~mm}$ and an average temperature of $15.8^{\circ} \mathrm{C}$ (Iranian meteorological organization, 1997-2006).

\subsection{General Characteristics}

For evaluating earthquake damage and losses, many systems are designed e.g. PAR model (Pressure and Release) is pointed out by JICA (2000). Some of the methods rely on the methods of urban planning, land usage and degree of urban fabric development so that the places in urban spaces with high and low risk can be determine. The mathematical fractal model and fuzzy model are also expertly used. The common feature of most researches is to determine the effect of natural structures including environmental hazards and ecological techniques in relation to GIS (Baz and Geymen, 2009). In this paper, we obtained physical and functional parameters of urban fabric based on each district of the Mashhad municipality. For this purpose, the following eight parameters are defined and processed in GIS: (1) open spaces ratio, (2) lands differentiation, (3) population density, (4) occupied area, (5) age of buildings, (6) deteriorated fabrics, (7) proximity to faults, and (8) seismic grading (Table 1). The weighting values of these parameters calculated by using AHP and then combined with standardized parameters in the evaluation system.

\subsection{Quantitative Models}

Analytic hierarchy process (AHP), as a theory for dealing with complex, technological, economical, and socio-political problems (Saaty, 1980; Saaty and Vargas, 2001) is an appropriate method for deriving the weight assigned to each factor. AHP is a multi-objective, multi-criteria decision-making approach to arrive at a scale of preference among a set of alternatives. In AHP method, an index of consistency, known as the Consistency Ratio (CR), which is a ratio between the matrix's consistency index and random index. CR is used to indicate the probability that the matrix judgments were randomly generated (Saaty 1977).

$$
C R=\frac{C I}{R I}
$$

where RI is the average of the resulting consistency index, depending on the order of the matrix given by Saaty (1977) and $\mathrm{CI}$ is the consistency index and can be expressed as:

$$
C I=\frac{\left(\lambda_{\max }-n\right)}{(n-1)}
$$

where, $\lambda \max$ is the largest or principal eigenvalue of the matrix and can be easily calculated from the matrix, and $n$ is the order of the matrix. CR ranges from 0 to 1 . A CR close to
1 indicates the probability that the matrix's rating was randomly generated. A CR of the order of 0.1 or less is a reasonable level of consistency (Saaty 1977). A CR above 0.1 requires revision of the judgments in the matrix because of an inconsistent treatment of particular factor ratings. In this case the CR of the matrix of paired comparisons between the fifteen influential factors in our landslide susceptibility assessment is 0.083 , and is thus acceptable. The standard combined method is based on statistical techniques that by the change of variable data make it possible for data to be non-dimensional and algebraic combining for each land unit as follows:

$$
z=\frac{(x-\mu)}{\delta}
$$

where, $\mu$ is the mean data of parameters $(\mathrm{x}), \delta$ is the standard deviation, and $\mathrm{z}$ is the indication of data standardization.

\section{Results and Discussion}

In this study, the municipality districts as the land units, considered to present the final vulnerability zonation map. On this basis, we used the eleven districts including the central business district of Mashhad. The selected indicators extracted and calculated in to each district by using GIS (Table 2). In the first step after preparing primary pair-wise matrix, we calculated the geometric mean of each row and then their normal weight, to be used as the standard weight of each indicator in AHP (Table 3). In the second step, in order to test the consistency of indicator weights, the consistency ratio (CR) determined as 0.0835 which indicates an acceptable consistency level in binary comparison of obtained weights $(\mathrm{CR}<0.1)$. The parameters analysis using AHP exhibited the weighty value for lands differentiation, Proximity to faults and Population density, respectively. In this stage before to combine the calculated and weighted parameters, the indicators standardized according to equation (3). These standardized values multiplied with AHP weighting values due to get the new indicator (Figure 4). The advantage of this type of multiplication and indicator reformation is the reduction of empirical pair-wise factual errors. Nevertheless, the new indicator values combined in to each municipality district (Figure 5). The figure 4 presented the vulnerability of urban fabric against earthquake hazard. Based on this figure, we can say that 1 . the $\mathrm{CBD}$ and districts of 8,3 and 4 of Mashhad municipality have the most fabric vulnerability against earthquakes, respectively, 2. the urban texture of the municipal districts of 9, 7,6 and 10 have less vulnerability against earthquakes, respectively, 3 . the regression results between final zoning and the above mentioned parameters revealed strong correlation $\left(\mathrm{R}^{2}=0.75\right)$ between deteriorated urban fabrics and the final zonation map $(\mathrm{P} \geq 0.95)$. Quantitative analysis of the estimated indicator leaded to produce the zonation map of earthquake vulnerability for each municipality districts of Mashhad city (Figure 5). This map made in ArcGIS ver.9.3 and prepared after the combining of AHP and Standard score models. 
Table 1. The selected indicators

\begin{tabular}{clcl}
\hline No. & Parameter & Unit & Attribution \\
\hline 1 & Open spaces ratio & ha & Surface area of bare grounds, roads and streams \\
2 & Lands differentiation & $\mathrm{m} 2$ & Average size of residential lands differentiation \\
3 & Population density & $\mathrm{p} / \mathrm{ha}$ & Ratio of residential population to land being used \\
4 & Occupied area & $\%$ & $\%$ of buildings with $>180 \%$ level occupation \\
5 & Age of buildings & $\%$ & $\%$ of buildings with $>20$ years of age \\
6 & Deteriorated fabrics & ha & Surface area of deteriorated urban fabrics \\
7 & Proximity to faults & $\mathrm{km}$ & Distance of the district center to the nearest fault \\
8 & Seismic grading & $\%$ & Probability of earthquake occurrence grading \\
\hline
\end{tabular}

Table 2. Determination of the indicators for each municipality district

\begin{tabular}{|c|c|c|c|c|c|c|c|c|}
\hline districts & $\begin{array}{l}\text { open } \\
\text { spaces } \\
\text { (ha) }\end{array}$ & $\begin{array}{c}\text { lands } \\
\text { differentiation } \\
(\mathrm{m} 2)\end{array}$ & $\begin{array}{c}\text { population } \\
\text { density } \\
\text { (p/ha) }\end{array}$ & $\begin{array}{c}\text { occupied } \\
\text { area } \\
(\%) \\
\end{array}$ & $\begin{array}{c}\text { Age of } \\
\text { buildings } \\
(\%)\end{array}$ & $\begin{array}{c}\text { deteriorated } \\
\text { fabrics } \\
\text { (ha) }\end{array}$ & $\begin{array}{l}\text { proximity to } \\
\text { faults } \\
(\mathbf{k m}) \\
\end{array}$ & $\begin{array}{c}\text { seismic } \\
\text { grading } \\
(\%)\end{array}$ \\
\hline 1 & 897 & 305 & 167 & 10 & 49 & 140 & 3 & 75 \\
\hline 2 & 2410 & 185 & 240 & 4 & 66 & 620 & 1 & 85 \\
\hline 3 & 1333 & 151 & 295 & 3 & 79 & 820 & 1.5 & 20 \\
\hline 4 & 610 & 127 & 256 & 0.5 & 6 & 705 & 3 & 35 \\
\hline 5 & 1290 & 181 & 183 & 0 & 84 & 770 & 1 & 20 \\
\hline 6 & 1494 & 154 & 190 & 0.5 & 32 & 535 & 1 & 25 \\
\hline 7 & 2867 & 188 & 51 & 3 & 43 & 200 & 6 & 65 \\
\hline 8 & 776 & 228 & 119 & 12 & 57 & 390 & 6 & 70 \\
\hline 9 & 3086 & 285 & 120 & 14 & 26 & 40 & 6 & 80 \\
\hline 10 & 1415 & 266 & 160 & 7.5 & 66 & 30 & 1.5 & 60 \\
\hline 11 & 802 & 252 & 183 & 18 & 28 & 0 & 3 & 55 \\
\hline CBD & 55 & 186 & 128 & 6 & 70 & 270 & 1.5 & 20 \\
\hline
\end{tabular}

Table 3. the standardized weights of each parameter based on AHP

\begin{tabular}{|c|c|c|c|c|c|c|c|c|c|}
\hline Factors & (1) & (2) & (3) & (4) & (5) & (6) & (7) & (8) & Weight \\
\hline (1) Open spaces ratio & 1.00 & & & & & & & & 0.0819 \\
\hline (2) Lands differentiation & 4.00 & 1.00 & & & & & & & 0.2123 \\
\hline (3) Population density & 2.00 & 0.50 & 1.00 & & & & & & 0.1401 \\
\hline (4) Occupied area & 1.00 & 0.25 & 0.33 & 1.00 & & & & & 0.0542 \\
\hline (5) Age of buildings & 0.25 & 0.50 & 0.33 & 2.00 & 1.00 & & & & 0.1060 \\
\hline (6) Deteriorated fabrics & 2.00 & 0.25 & 0.50 & 3.00 & 1.00 & 1.00 & & & 0.1024 \\
\hline (7) Proximity to faults & 2.00 & 2.00 & 2.00 & 3.00 & 0.50 & 2.00 & 1.00 & & 0.1722 \\
\hline (8) Seismic grading & 2.00 & 1.00 & 2.00 & 2.00 & 0.33 & 1.00 & 1.00 & 1.00 & 0.1309 \\
\hline Consistency ratio & & & & & & & & & 0.0835 \\
\hline
\end{tabular}

Examination of the correlation test by using the Pearson test was indicated that the final zonation results with $\mathrm{P} \geq 0.95$ have the most powerful and significant relationship between the factor of the deteriorated fabrics and open spaces ratio $\left(\mathrm{R}^{2}=0.75\right)$. Therefore, it seems the existence of deteriorated fabrics at the study area is affecting factor to decline the fabric sustainability and is causing to increase of fabric vulnerability against earthquakes.

\section{Conclusions}

At the present study, we used the eight parameters for earthquake vulnerability zonation. Our aim was to identify the urban fabric susceptibility of Mashhad against earthquakes by combining the AHP and the standard score models. The results revealed that Mashhad CBD and districts of 8,3 and 4 of Mashhad municipality have the most fabric vulnerability against earthquakes, respectively, while the urban texture of the municipal districts of $9,7,6$ and 10 have less vulnerability against earthquakes, respectively. The used methodology could be applied for urban risk management in the Mashhad City.

\section{Acknowledgements}

We thank Islamic Azad University, Mashhad branch for their support of the project. 


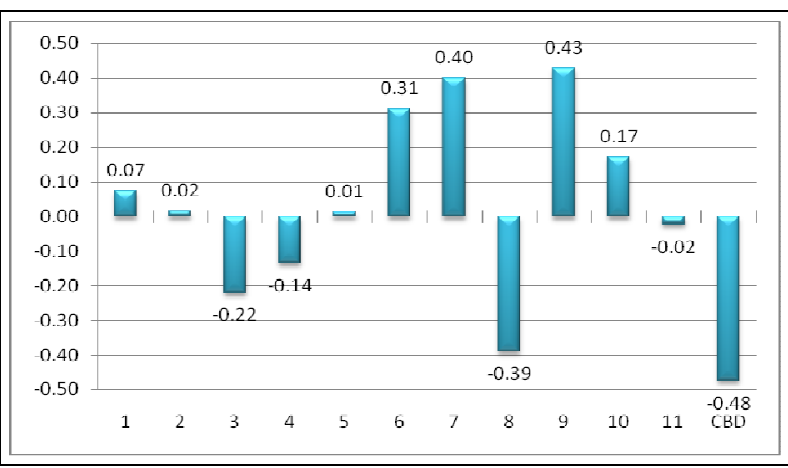

Figure 4. Statistical estimations of earthquake vulnerability for each municipality districts of Mashhad after combining of AHP and Standard score models

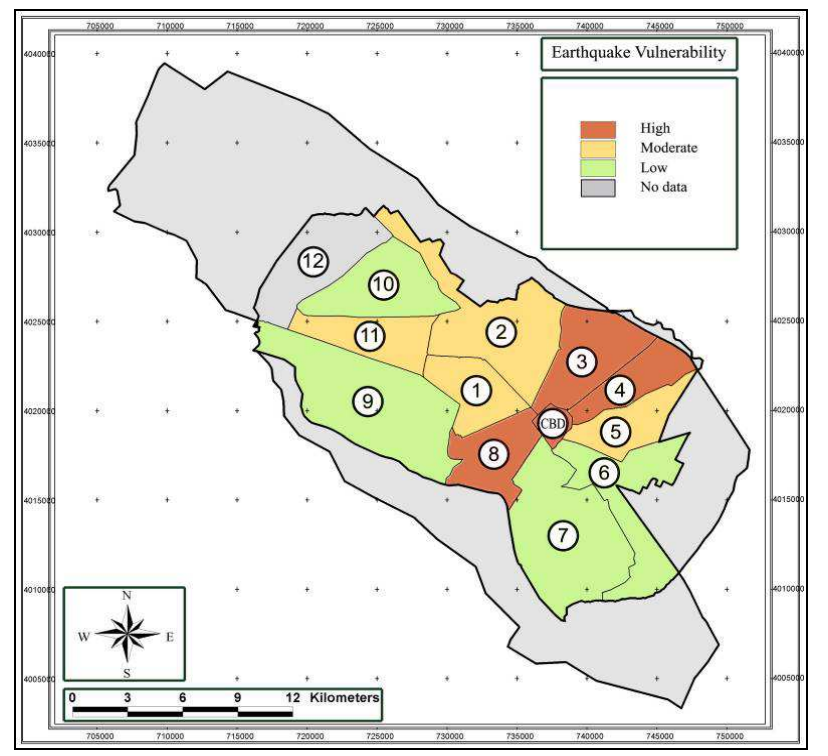

Figure 5. Earthquake zonation of vulnerability for each municipality districts of Mashhad

\section{References}

[1] Baz I, Geymen A (2009). Development and application of GIS-based analysis/ synthesis modeling techniques for urban planning of Istanbul Metropolitan Area, Advances in Engineering Software 40(2):128-140.

[2] Clark JK, McChesney R, Munroe DK, Irwin EG (2009). Spatial characteristics of exurban settlement pattern in the United States, Landscape and Urban Planning 90(3-4):178-188.

[3] Crichton D, Salt JE (2001). The implications of climate change for the insurance industry: an update and outlook to 2020, Building Research Establishment, Watford, England. $69 \mathrm{pp}$.

[4] Cutter SL, Mitchell JT (2000). Revealing the vulnerability of people and places: a case study of Georgetown County, South Carolina, Annals of the Association of American Geographers 90 (4):713-737.

[5] De Leon JCV (2006). Vulnerability a conceptual and methodological review, United Nations University Institute for Environment and Human Security. 64 pp.
[6] Fedeski M, Gwilliam J (2007). Urban sustainability in the presence of flood and geological hazards: The development of a GIS-based vulnerability and risk assessment methodology, Landscape and Urban Planning 83(1):50-61.

[7] Gueguen P, Michel C, LeCorre L (2007). A simplified approach for vulnerability assessment in moderate-to-low seismic hazard regions: application to Grenoble (France), Bulletin of Earthquake Engineering 5(3):467-490.

[8] Geological survey of Iran, Geological sheet of k-4, Scale 1:250,000. via http://www.gsi.ir.

[9] Geological survey of Iran, Topographical sheets of 79623 , 79624, 78621 and 78623, Scale 1:50,000. via http://www.gsi.ir.

[10] Giammarinaro MS, Alletti M, Azzara RM, Canzoneri V, Maiorana S, Rovelli A, Tertulliani A, Vallone P (2003). Natural hazard assessment through an oriented GIS. Geophysical Research Abstracts 5:12961

[11] Inel M, Senel SM, Toprak S, Manav Y (2008). Seismic risk assessment of buildings in urban areas: a case study for Denizli, Turkey. Natural Hazards 46(3):265-285.

[12] Iranian meteorological organization; IRIMO, Statistical information of Mashhad synoptic station, in a 10-year time period of 1997-2006. via http://www.irimo.ir.

[13] Japan International Cooperation Agency; JICA (2000). The study on seismic micro-zoning of greater Tehran area in the Iran, Tehran municipality, Iran.

[14] Lantada N, Pujades LG, Barbat A (2003). Vulnerability and seismic damage scenarios for Barcelona (Spain) by using GIS, Geophysical Research Abstracts 5:09103.

[15] Martelli L, Filippini M, Bagli S, Severi P, Tomasseti F (2007). Seismic risk reduction: a local effects map for territorial and urban planning; The example of the Rimini Territorial plan. Bollettino di Geofisica Teorica e Applicata 48(2):151-162.

[16] Menoni, S., (2001). Chains of damages and failures in a metropolitan environment: Some observations on the Kobe earthquake in 1995. Journal of Hazardous Materials 86(1-3):101-119.

[17] Hampton SD, Lee JS, Tolbert NL, McLaren TM, Navarro CM, Myers JD, Spencer BF, Elnashai AS (2008). MAEviz: bridging the time-from discovery gap between seismic research and decision making, Proceedings of 4th IEEE international conference on e-science, Indianapolis, 7-12 Dec 2008.

[18] Paskaleva, I, Silvia D, Panza Giuliano GF, Franco V (2007). An earthquake scenario for the micro zonation of Sofia and the vulnerability of structures designed by use of the Eurocodes, Soil Dynamics and Earthquake Engineering 27(11):1028-1041.

[19] Petermans T, Devleeschouwer X, Pouriel F, Rosset P (2006). Mapping the local seismic hazard in the urban area of Brussels, Belgium. Proceedings of the 10th IAEG congress, Nottingham.

[20] Prowse, M., (2003). Towards a clear understanding of vulnerability in relation to chronic poverty. Chronic poverty research centre working paper, University of Manchester 24. 
[21] Ren AZ, Xie XY (2004). The simulation of post-earthquake fire-prone area based on GIS, Journal of Fire Sciences, 22(5):421-439.

[22] Saaty TL, Vargas LG (2001). Models, methods, concepts, and applications of the analytic hierarchy process. Kluwer Academic, Boston. 333 pp.

[23] Saaty TL (1977). A scaling method for priorities in hierarchical structures. Journal of Mathematical Psychology 15(3):234- 281.

[24] Saaty TL, (1980). The analytical hierarchy process. McGraw Hill, New York, 350 pp.

[25] Statistical Centre of Iran, (2006). Macro results of statistical survey. via http://www.amar.org.ir.

[26] Turner BL, Kasperson RE, Matson PA, McCarthy JJ, Corell RW, Christensen L, Eckley N, Kasperson J, Luers A, Martello ML, Polsky C, Pulsipher A, Schiller A (2003). A framework for vulnerability analysis in sustainability science. Proceedings of the National Academy of Sciences of the United States of America, 100(14): 8074-8080.
[27] Umemura K., Murao O, Yamazaki F (2000). Development of GIS-based building damage database for the 1995 Kobe earthquake. Proceedings of 21th Asian conference on remote sensing, Taipei, Taiwan.

[28] Voulgaris N, Vassilakis E, Parcharidis I, Soukis K, Alexopoulos J (2003). A GIS based application for seismic risk operational response support. Geophysical Research Abstracts 5:10195.

[29] Xu F, Chen X, Aizhu R, Xinzheng L (2008). Earthquake disaster simulation for an urban area, with GIS, CAD, FEA and VR integration. Proceedings of the 12th international conference on computing in civil and building engineering, Beijing, China.

[30] Youhai G, Qimin F, Jing j (2006). A GIS-based earthquake and tsunami emergency command system for seaside cities. Journal of Ocean University of China 5(2):181-186.

[31] Zaincenco A, Alkaz V (2005). Urban seismic risk studies with utilization of GIS. NATO advanced workshop on "foresight, precaution and risk: preparing for the unexpected", Chisinau, Republic of Moldova. 